\title{
Coronary artery bypass graft surgery-care globalization: The impact of national care on fatal and nonfatal outcome
}

\author{
Elisabeth Ott, MD, a,c C. David Mazer, MD, a,d Iulia C. Tudor, PhD, ${ }^{b}$ Linda Shore-Lesserson, MD, a,e \\ Stephanie A. Snyder-Ramos, MD, ${ }^{\text {a,f }}$ Barry A. Finegan, MB, ${ }^{a, g}$ Patrick Möhnle, MD, ${ }^{a, c}$ Charles B. Hantler, MD, ${ }^{a, h}$ \\ Bernd W. Böttiger, MD, ${ }^{a, f}$ Ray D. Latimer, MA, MBBS, FRCA, ${ }^{a, i}$ Warren S. Browner, MD, MPH, Jack Levin, MD, ${ }^{a, k}$ and \\ Dennis T. Mangano, PhD, MD, for the Multicenter Study of Perioperative Ischemia Research Group and the Ischemia \\ Research and Education Foundation*
}

From the Multicenter Study of Perioperative Ischemia Research Group, ${ }^{\text {a }}$ San Bruno, Calif; Ischemia Research and Education Foundation, ${ }^{\mathrm{b}}$ San Bruno, Calif; Departments of Anesthesiology, Ludwig-Maximilians-University, ${ }^{\mathrm{c}}$ Munich, Germany; St Michael's Hospital, University of Toronto, ${ }^{d}$ Toronto, Canada; Montefiore Medical Center, ${ }^{\mathrm{e}}$ New York, NY; University of Heidelberg, ${ }^{\mathrm{f}}$ Germany; University of Alberta, Edmonton, ${ }^{g}$ Alberta, Canada; Washington University School of Medicine, ${ }^{\text {h }}$ St Louis, Mo; Papworth Hospital, ${ }^{\mathrm{i}}$ Cambridge, United Kingdom; California Pacific Medical Center Research Institute, ${ }^{j}$ San Francisco, Calif; Department of Laboratory Medicine, University of California School of Medicine, ${ }^{\mathrm{k}}$ San Francisco, Calif.

Received for publication April 26, 2005; revisions received Nov 8, 2006; accepted for publication Dec 6, 2006.

Address for reprints: Elisabeth Ott, MD, c/o Editorial Office, The Ischemia Research and Education Foundation, 1111 Bayhill Drive, Suite 480, San Bruno, CA 94066 (E-mail: diane@ @iref.org).

*See Appendix for a complete list of the Investigators and Centers. www.iref.org

J Thorac Cardiovasc Surg 2007;133:1242-51 $0022-5223 / \$ 32.00$

Copyright $\odot 2007$ by The American Association for Thoracic Surgery

doi:10.1016/j.jtcvs.2006.12.031
Objective: In an international, prospective, observational study, we contrasted adverse vascular outcomes among four countries and then assessed practice pattern differences that may have contributed to these outcomes.

Methods: A total of 5065 patients undergoing coronary artery bypass graft surgery were analyzed at 70 international medical centers, and from this pool, 3180 patients from the 4 highest enrolling countries were selected. Fatal and nonfatal postoperative ischemic complications related to the heart, brain, kidney, and gastrointestinal tract were assessed by blinded investigators.

Results: In-hospital mortality was $1.5 \%(9 / 619)$ in the United Kingdom, $2.0 \%(9 / 444)$ in Canada, $2.7 \%$ (34/1283) in the United States, and 3.8\% (32/834) in Germany ( $P=$ $.03)$. The rates of the composite outcome (morbidity and mortality) were $12 \%$ in the United Kingdom, $16 \%$ in Canada, $18 \%$ in the United States, and 24\% in Germany $(P<$ .001). After adjustment for difference in case-mix (using the European System for Cardiac Operative Risk Evaluation) and practice, country was not an independent predictor for mortality. However, there was an independent effect of country on composite outcome. The practices that were associated with adverse outcomes were the intraoperative use of aprotinin, intraoperative transfusion of fresh-frozen plasma or platelets, lack of use of early postoperative aspirin, and use of postoperative heparin.

Conclusions: Significant between-country differences in perioperative outcome exist and appear to be related to hematologic practices, including administration of antifibrinolytics, fresh-frozen plasma, platelets, heparin, and aspirin. Understanding the mechanisms for these observations and selection of practices associated with improved outcomes may result in significant patient benefit.

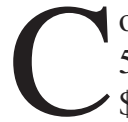
oronary artery bypass graft $(\mathrm{CABG})$ surgery was introduced approximately 50 years ago and is now performed in 1 million patients at a cost exceeding $\$ 20$ billion annually. As a technically complex procedure that is performed in high-risk patients, it has been scrutinized closely, resulting in substantial standardization of surgical, anesthetic, and postoperative care. ${ }^{1-5}$ Consequently, one would expect that case-mix adjusted cardiovascular mortality and morbidity would be similar among high-volume centers, despite national differences in health care systems and reimbursement practices. ${ }^{6-8}$ However, there are few, if any, comprehensive, international data sets that allow comparison of the effects of countryspecific, system-associated factors, such as length of stay, time from diagnosis to surgery, and variations in the pharmacologic management of hemostasis on morbidity and mortality, although these factors vary markedly depending on where CABG surgery is performed. ${ }^{8-13}$ 


\section{Abbreviations and Acronyms \\ $\mathrm{CABG}=$ coronary artery bypass graft \\ EuroSCORE $=$ European System for Cardiac \\ Operative Risk Evaluation}

The primary aim of this analysis was to determine and contrast the adverse vascular outcomes that occurred after CABG surgery among 4 countries; our hypothesis was that vascular outcomes differed among countries. Our secondary hypothesis was that practice pattern differences existed and accounted for between-country differences in outcome. The target population was patients undergoing elective CABG surgery (primary or repeat) or combined CABG-valve surgery (replacement or repair) among institutions of 4 countries, the United States, Canada, the United Kingdom, and Germany. Patients were randomly sampled by center, and a comprehensive set of individual perioperative data were collected, to allow definition of practice by center and by country.

\section{Materials and Methods}

Enrollment in the Multicenter Study of Perioperative Ischemia Research Group EPI II Study began in November 1996, and the in-hospital phase ended in June 2000. A total of 5436 patients scheduled for CABG surgery were enrolled in 72 medical institutions among 17 countries (4 continents). Details of the EPI II study have been described. ${ }^{14}$ Specifically, at each institution, after institutional review board approval, 100 patients were to be enrolled prospectively according to a systematic sampling scheme. To be eligible for enrollment, the patient had to be scheduled to undergo CABG using cardiopulmonary bypass, had to complete the preoperative interview, had to be at least 18 years old, could not be enrolled in another study or clinical trial, and had to give written informed consent.

\section{Clinical Care}

Clinical decisions were not controlled by the study protocol, and all patients qualifying for enrollment within the prespecified enrollment period were entered. Of the 5436 patients enrolled, 371 were excluded from the analysis for the following reasons: withdrawal from the study (32 patients), death before surgery (2 patients), cancellation or rescheduling of the surgery (97 patients), change in procedure (132 patients), incomplete data (97 patients), or inadvertent enrollment in another study (11 patients).

\section{Study Data}

For our comparison, we chose the 4 highest enrolling countries to obtain the largest and most homogeneous samples of patients undergoing elective CABG surgery. All surgery in these countries was performed at university or university-affiliated teaching hospitals. The distribution of the patients was as follows: United States (29 centers; $\mathrm{n}=1283$ ); Germany (9 centers; $\mathrm{n}=834$ ); United Kingdom ( 7 centers; $n=619$ ); and Canada ( 8 centers; $n=444$ ).

For each enrolled patient, more than 7500 fields of data were collected, including demographic, historical, clinical, laboratory, electrocardiographic, special testing, resource use, and adverse outcome data. Independent investigators coded all medications received throughout hospitalization from admission to discharge or until death. All data fields for each patient were examined centrally for completeness and accuracy, with all changes documented before formal in-hospital database closure on October 15, 2001.

\section{Measurement of Outcomes}

All outcomes were prespecified by protocol and diagnosed by independent and blinded investigators. Fatal and nonfatal outcomes were classified as cardiac (myocardial infarction, heart failure), cerebral (stroke, encephalopathy), renal (dysfunction, failure), gastrointestinal (ischemia, infarction), or other adverse event complications. ${ }^{14}$ The diagnosis of myocardial infarction required ${ }^{15}$ the development of new Q waves (as defined by Minnesota Code 1-1-1 up to 1-2-7), new persistent ST-segment or T-wave changes (Minnesota Code 9-2, 4-1, 4-2, 5-1, or 5-2) associated with an elevation of creatine kinase-myocardial band isoenzyme values, or autopsy evidence of acute myocardial infarction. The diagnosis of heart failure required the use of a ventricular assist device, the use of continuous inotropic support for at least 24 hours, or autopsy verification of heart failure. Cerebral outcomes were classified ${ }^{16}$ as clinically diagnosed stroke or encephalopathy, or computed tomography, magnetic resonance imaging, or autopsy evidence of a focal or global lesion. Renal dysfunction was defined ${ }^{17}$ as a serum creatinine level of $2.00 \mathrm{mg} / \mathrm{dL}$ or greater accompanied by a 0.7 $\mathrm{mg} / \mathrm{dL}$ or greater increase over baseline; renal failure was defined as dysfunction requiring dialysis or autopsy verification of renal failure. Gastrointestinal ischemia ${ }^{18}$ was defined as abdominal pain likely associated with bowel ischemia; gastrointestinal infarction was defined by bowel resection or evidence of intestinal infarction on autopsy. In addition, we defined a composite outcome consisting of mortality and/or any of the morbidities: myocardial infarction, congestive heart failure, stroke, encephalopathy, renal dysfunction, renal failure, and gastrointestinal ischemia/infarction.

\section{Statistical Analysis}

The prevalence of clinical characteristics and the incidence of individual adverse events comprising the composite outcome (death, myocardial infarction, congestive heart failure, stroke, encephalopathy, renal dysfunction, renal failure, or gastrointestinal ischemia/infarction) among the 4 countries were compared using the chi-square test. Continuous variables (eg, time to surgery and length of hospital stay) were compared using nonparametric tests.

The European System for Cardiac Operative Risk Evaluation (EuroSCORE) ${ }^{19}$ (one of the most common risk stratification systems for cardiac surgical patients) and other potential risk factors for adverse outcomes were investigated first using univariate logistic regression analysis. All risk factors statistically significant at $P$ less than .20 in univariate analysis were then entered into a multivariate logistic regression model. Stepwise logistic regression was performed, with variables retained that were significant at a 2-tailed nominal $P$ value of less than .05. To investigate the differences among countries, adjusting for their differences in risk profile, separate risk models were developed for mortality, morbidity, early morbidity (within 48 hours postsurgery), and late morbidity (after 48 hours postsurgery). All statistical analyses 
TABLE 1. Baseline demographic and medical characteristics of the $\mathbf{3 1 8 0}$ study patients

\begin{tabular}{|c|c|c|c|c|c|}
\hline Characteristic & $\begin{array}{l}\text { United Kingdom } \\
\qquad(\mathrm{n}=619)\end{array}$ & $\begin{array}{l}\text { Canada } \\
(\mathrm{n}=444)\end{array}$ & $\begin{array}{l}\text { United States } \\
\text { (n = 1283) }\end{array}$ & $\begin{array}{l}\text { Germany } \\
(\mathrm{n}=\mathbf{8 3 4})\end{array}$ & $P$ value \\
\hline \multicolumn{6}{|l|}{ Demographic and clinical variables } \\
\hline \multicolumn{6}{|l|}{ Age $(y)$} \\
\hline Mean \pm SD & $62 \pm 9.0$ & $64 \pm 9.9$ & $64 \pm 9.9$ & $64 \pm 9.0$ & \\
\hline Median & $63.9 *$ & 66.1 & 65.2 & 64.3 & $<.001$ \\
\hline Patients aged $>70$ y, n (\%) & $141(22.8)^{*}$ & $147(33.1)$ & $415(32.4)$ & $262(31.4)$ & $<.001$ \\
\hline \multicolumn{6}{|l|}{ Weight $(\mathrm{kg})$} \\
\hline Mean \pm SD & $81.4 \pm 13.5$ & $82.0 \pm 15$ & $84.9 \pm 17.7$ & $79.9 \pm 12.0$ & \\
\hline Median & 80.1 & 80.55 & 83.0 & 79.5 & $<.001$ \\
\hline Body mass index $>30 \mathrm{~kg} / \mathrm{m}^{2}, \mathrm{n}(\%)$ & $165(26.8)$ & $151(34.0)$ & $569(44.5)^{*}$ & $179(21.6)$ & $<.001$ \\
\hline Female sex, n (\%) & $104(16.8)$ & $88(19.8)$ & $239(18.6)$ & $170(20.4)$ & .350 \\
\hline $\begin{array}{c}\text { African American or American Indian } \\
\text { or Hispanic ethnic group, } \mathrm{n}(\%)\end{array}$ & $1(0.2)$ & $11(2.5)^{*}$ & $183(14.3)^{*}$ & $0(0.0)$ & $<.001$ \\
\hline \multicolumn{6}{|l|}{ Medical history } \\
\hline Diabetes, n (\%) & $104(16.8)^{*}$ & $138(31.2)$ & $478(37.3)$ & $228(27.4)$ & $<.001$ \\
\hline History of smoking, $† \mathrm{n}(\%)$ & $494(80.1)^{*}$ & $310(69.8)$ & $922(72.1)$ & $594(71.3)$ & $<.001$ \\
\hline Current smoking, n (\%) & $49(7.9)$ & $51(11.5)$ & $201(15.7)^{*}$ & $89(10.7)$ & $<.001$ \\
\hline Unstable angina, $\mathrm{n}(\%)$ & $265(43.9)$ & $259(60.5)^{*}$ & $787(68.1)^{*}$ & $364(49.8)$ & $<.001$ \\
\hline $\mathrm{MI}, \mathrm{n}(\%)$ & $357(58.0)$ & $270(60.8)$ & $625(49.2)^{*}$ & $428(51.9)$ & $<.001$ \\
\hline CHF, n (\%) & $270(43.7)$ & $71(16.0)^{*}$ & $348(27.4)$ & $286(34.7)$ & $<.001$ \\
\hline PTCA, n (\%) & $44(7.1)^{*}$ & $91(20.5)$ & $263(20.6)$ & $147(17.7)$ & $<.001$ \\
\hline CABG, n (\%) & $23(3.7)$ & $31(7.0)$ & $122(9.5)^{*}$ & $34(4.1)$ & $<.001$ \\
\hline \multicolumn{6}{|l|}{ Preoperative diagnostic test results } \\
\hline Ejection fraction $<44 \%$, n $(\%)$ & $107(20.5)$ & $77(19.9)$ & $304(27.6)^{*}$ & $123(15.9)$ & $<.001$ \\
\hline \multicolumn{6}{|l|}{ Coronary disease location } \\
\hline Left main, $\mathrm{n}(\%)$ & $162(26.6)^{*}$ & $166(37.8)$ & $555(44.5)$ & $300(36.3)$ & $<.001$ \\
\hline Left anterior descending, $\mathrm{n}(\%)$ & $593(96.3)$ & $426(96.2)$ & $1229(97.3)$ & $800(96.0)$ & .362 \\
\hline Circumflex, n (\%) & $559(90.9)$ & $386(87.1)$ & $1130(90.3)$ & $757(90.8)$ & .151 \\
\hline Right, n (\%) & $570(92.5)$ & $398(90.5)$ & $1158(92.1)$ & $756(90.8)$ & .446 \\
\hline \multicolumn{6}{|l|}{ Medications at admission, $\mathrm{n}(\%)$} \\
\hline ACE inhibitors & $161(26.0)^{*}$ & $162(36.5)$ & $494(38.5)$ & $448(53.7)$ & $<.001$ \\
\hline Beta-blockers & $412(66.6)$ & $337(75.9)^{*}$ & $793(61.8)$ & $550(65.9)$ & $<.001$ \\
\hline Calcium channel blockers & $352(56.9)^{*}$ & $186(41.9)^{*}$ & $326(25.4)$ & $205(24.6)$ & $<.001$ \\
\hline Platelet inhibitors & $211(34.1)^{*}$ & $296(66.7)$ & $892(69.5)$ & $278(33.3)^{*}$ & $<.001$ \\
\hline
\end{tabular}

ACE, Angiotensin-converting enzyme; $C A B G$, coronary artery bypass graft; $C H F$, congestive heart failure; MI, myocardial infarction; PTCA, percutaneous transluminal coronary angiography; $S D$, standard deviation. *Country with statistically different prevalence $(P<.01$ with Bonferroni adjustment) in characteristic, by pairwise comparisons. $†$ Smoking is regular smoking of cigarettes, cigars, or pipe.

were performed with SAS Version 8.12 software (SAS Institute, Cary, NC).

The Ischemia Research and Education Foundation provided all funding for execution of the study, collection of the data, and analysis and publication of the findings.

\section{Results}

Patients typically had chronic and acute manifestations of vascular disease (Table 1). U.S. patients had the highest prevalence of body mass index greater than $30 \mathrm{~kg} / \mathrm{m}^{2}$, diabetes, unstable angina, prior $\mathrm{CABG}$, left main coronary artery disease, ejection fraction less than $44 \%$, and noncaucasian ethnicity. U.K. patients had a higher prevalence of heart failure and acute smoking cessation but were the youngest and least likely to have diabetes, unstable angina, left main coronary artery disease, and previous coronary intervention. Angiotensin-converting enzyme inhibitors were used most commonly in Germany and the United States, calcium channel blockers were used most commonly in the United Kingdom and Canada, and antiplatelet medications were used most commonly in the United States and Canada. On the basis of the EuroSCORE, the United Kingdom had the highest proportion of patients in the low-risk group, whereas the United States cohort had the highest proportion in the high-risk group (Figure 1). The differences among countries in the overall distribution of the EuroSCORE were significant $(P<.001)$. In addition, the process of care factors (Table 2) varied considerably among countries. 


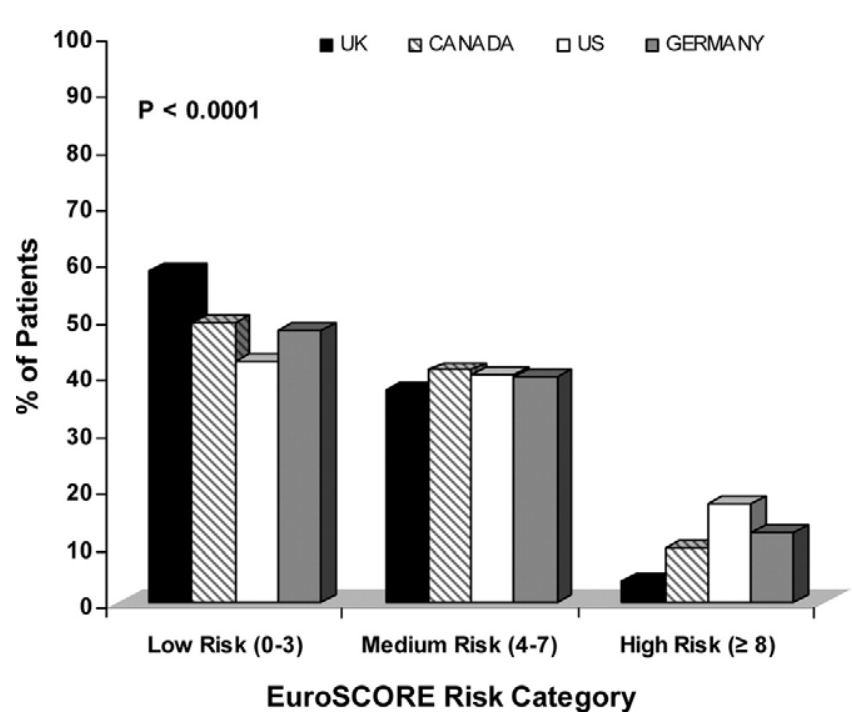

Figure 1. Comparison of EuroSCORE among 4 study countries. The distribution of the EuroSCORE (in low, medium, and high-risk groups) among 4 countries: United Kingdom, Canada, United States, and Germany. Data given in percentages. EuroSCORE, European System for Cardiac Operative Risk Evaluation.

\section{Between-country Differences in Outcome}

For mortality, unadjusted rates differed among countries (Table 3), but these differences did not survive multivariate logistic regression. For morbidity, we found significant differences among countries in cardiac, cerebral, and renal morbidity-but not gastrointestinal morbidity-as well as in overall composite outcome (Table 4). Multivariate logistic regression further demonstrated that the between-country differences in individual organ morbidities and composite morbidity remained significant.

\section{Multivariate Analysis of Composite Outcome (Within and After 48 Hours After Surgery)}

None of the individual admission/preoperative risk factors explained the inter-country differences in the risk of the composite outcome. Among intraoperative factors, administration of platelets (odds ratio $=1.6,95 \%$ confidence interval: $1.0-2.3, P=.03$ ) and fresh-frozen plasma (odds ratio $=1.5$, confidence interval: $1.0-2.2, P=.03$ ) were independently associated with the risk of the composite outcome, but neither of these eliminated the independent effect of country on composite outcome (Table 4). None of the process of care factors (Table 2) were independently associated with the composite outcome.

\section{Early Outcomes (Within 48 Hours)}

There were 338 patients with adverse events within 48 hours after surgery. After adjustment for significant confounders (admission, preoperative, and intraoperative fac- tors, including the EuroSCORE), country no longer had an independent effect on the risk of the composite outcome within 48 hours. Reversible risk factors for early composite outcome were the use of aprotinin and transfusion of freshfrozen plasma (Table 5, Figure 2).

Aprotinin use was most prevalent in Germany (69\%), compared with $23 \%$ in the United Kingdom, $20 \%$ in the United States, and only $6 \%$ in Canada. The risk of the composite outcome (within 48 hours of surgery) was $13.5 \%$ in those treated with aprotinin versus $9.3 \%(P<.001)$ for those who did not receive aprotinin. The administration of fresh-frozen plasma during surgery was most prevalent in Germany (11\%), followed by the United States (8\%), the United Kingdom (2\%), and Canada (1\%). Use of freshfrozen plasma was associated with more than a doubling of the risk of the composite outcome in this period $(24.9 \%$ vs $9.6 \%, P<.001)$. None of the process of care factors was independently associated with the early composite outcome. Platelets were used during surgery most frequently in the United States (12\%), followed by Germany (4\%), the United Kingdom (1.5\%), and Canada (0.75\%), but the administration of platelets during surgery was not associated with the risk of early adverse outcomes.

\section{Late Outcomes (After 48 Hours)}

Patients with early composite outcomes were excluded in analyses of the factors associated with the risk of late composite outcome. Early postoperative use (within 48 hours) of aspirin was associated with a reduced risk of late outcomes, whereas use of intravenous heparin increased the risk (Table 6). The use of aspirin was most prevalent in Canada (83\%), followed by the United Kingdom (70\%), the United States (67\%), and Germany (42\%) (Figure 3). The administration of heparin was most prevalent in Germany (75\%), followed by Canada $(40 \%)$, the United Kingdom (17\%), and the United States (15\%).

\section{Resource Use}

Time on the waiting list for surgery differed significantly among countries, with the United Kingdom showing the longest time on the wait list (207 days), followed by Canada (37 days), Germany (21 days), and the United States (6 days) (Table 2). These findings were consistent across EuroSCORE risk groups. For all countries, higher risk groups (vs lower risk groups) were associated with shorter wait time. However, time on the wait list did not account for EuroSCORE differences.

There were significant inter-country differences in all intraoperative and postoperative time-related factors (Table 2). The United Kingdom had the shortest median bypass and crossclamp times (71 minutes and 38 minutes, respectively) in contrast with the United States (104 minutes and 69 minutes, respectively) and Germany (98 minutes and 58 minutes, respectively). After correction for the 
TABLE 2. Resource use and timelines

\begin{tabular}{|c|c|c|c|c|c|}
\hline Resource use & $\begin{array}{l}\text { United Kingdom } \\
\qquad(\mathrm{n}=619)\end{array}$ & $\begin{array}{l}\text { Canada } \\
\text { (n = 444) }\end{array}$ & $\begin{array}{l}\text { United States } \\
\qquad(\mathrm{n}=1283)\end{array}$ & $\begin{array}{l}\text { Germany } \\
(\mathrm{n}=834)\end{array}$ & $P$ value \\
\hline \multicolumn{6}{|l|}{ Timelines (median) } \\
\hline Time on wait list (d) overall & 206.5 & 37.0 & 6.0 & 21.0 & $<.001$ \\
\hline EuroSCORE 0-3 (low risk) & 221 & 37 & 7 & 23 & $<.001$ \\
\hline EuroSCORE 4-7 (medium risk) & 196 & 46 & 6 & 19 & $<.001$ \\
\hline EuroSCORE $\geq 8$ (high risk) & 74 & 36 & 3 & 18 & $<.001$ \\
\hline Time preoperatively (h) & 22.5 & 23.9 & 25.8 & 95.6 & $<.001$ \\
\hline Time of anesthesia (min) & 219.0 & 226.0 & 314.0 & 293.0 & $<.001$ \\
\hline Time in OR (min) & 170.0 & 170.0 & 246.0 & 213.0 & $<.001$ \\
\hline Time on CPB (min) & 71.0 & 72.5 & 104.0 & 98.0 & $<.001$ \\
\hline Time of crossclamp (min) & 38.0 & 44.0 & 69.0 & 58.0 & $<.001$ \\
\hline Time ICU stay (h) & 21.3 & 26.5 & 32.5 & 39.8 & $<.001$ \\
\hline Time ICU discharge to hospital discharge (d) & 5.0 & 4.0 & 4.0 & 8.0 & $<.001$ \\
\hline \multicolumn{6}{|l|}{ Intraoperative blood products transfusion } \\
\hline Transfusion of platelets in $\mathrm{OR}, \mathrm{n}(\%)$ & $9(1.5)^{*}$ & $3(0.7)^{*}$ & $151(11.8)$ & $33(4.0)$ & $<.001$ \\
\hline Number of units, mean (SD); median & $1.1(0.6) ; 1$ & $6.3(1.5) ; 6$ & $6.9(5.9) ; 6$ & $4.6(2.4) ; 5$ & \\
\hline Transfusion of RBC in OR, $\mathrm{n}(\%)$ & $119(19.2)$ & $71(16.0)$ & $515(40.2)^{*}$ & $397(47.6)^{*}$ & $<.001$ \\
\hline No. of units, mean (SD); median & $1.6(0.8) ; 1$ & $1.8(1.3) ; 2$ & $2.5(1.7) ; 2$ & $2.8(2.3) ; 2$ & \\
\hline Transfusion fresh-frozen plasma in $0 \mathrm{R}, \mathrm{n}(\%)$ & $15(2.4)^{*}$ & $6(1.4)^{*}$ & $108(8.4)$ & $88(10.6)$ & $<.001$ \\
\hline No. of units, mean (SD); median & $1.9(0.3) ; 2$ & $3.0(1.1) ; 3$ & $3.3(3.0) ; 2$ & $3.3(1.6) ; 3$ & \\
\hline Blood loss within $24 \mathrm{~h}$ postsurgery $(\mathrm{mL})$, mean (SD); median & 765 (598); 630 & $697(524) ; 600^{*}$ & $782(621) ; 640$ & $823(677) ; 680$ & $<.001$ \\
\hline Aprotinin used in $\mathrm{OR}, \mathrm{n}(\%)$ & $143(23.1)$ & $25(5.7)^{*}$ & $250(19.5)$ & $578(69.3) \dagger$ & $<.001$ \\
\hline Return to OR, n (\%) & $30(4.9)$ & $23(5.2)$ & $69(5.4)$ & $68(8.2)$ & .021 \\
\hline \multicolumn{6}{|l|}{ Medication within $48 \mathrm{~h}$ postsurgery, n (\%) } \\
\hline Aspirin & $435(70.3)$ & $369(83.1)$ & $863(67.3)$ & $346(41.5)^{*}$ & $<.001$ \\
\hline Heparin & $106(17.1)$ & $179(40.3)$ & $198(15.4)$ & $622(74.6)^{*}$ & $<.001$ \\
\hline
\end{tabular}

CPB, Cardiopulmonary bypass; ICU, intensive care unit; EuroSCORE, European System for Cardiac Operative Risk Evaluation; OR, operating room; $R B C$, red blood cell; $S D$, standard deviation. All data are given as median. Time preoperatively (h) denotes hours from admission to hospital to operating room admission. *Country with statistically different prevalence $(P<.01$ with Bonferroni adjustment $)$ in characteristic, by pairwise comparisons. $\dagger$ Country with statistically different prevalence in characteristic ${ }^{*}$ vs $\dagger$ are also statistically different).

number of bypass grafts, these times remained longer in the United States and Germany than in the United Kingdom or Canada.

\section{Discussion}

We compared serious adverse vascular outcomes among 4 countries and attempted to associate the practice patterns of each of those countries with those outcomes. Among the United States, German, United Kingdom, and Canadian centers, we found significant differences in outcomes and processes of care, most notably approaches to hemostasis. Practices that were associated with adverse outcomes included the intraoperative use of aprotinin and transfusion of fresh-frozen plasma or platelets, and the use of heparin or lack of administration of aspirin during the early postoperative period. Understanding the mechanisms for these observations and the selection of practices associated with improved outcomes may result in significant patient benefit.

Transfusion practices for red blood cells and blood products have been reported to vary widely between institutions and countries, ${ }^{20-22}$ ranging from $0 \%$ to $97 \%$ for fresh-frozen plasma. Prophylactic plasma administration has not been shown to reduce red cell transfusion, ${ }^{23-29}$ and recent studies have reported an independent risk of stroke and death after platelet or plasma transfusions..$^{20,30}$ The association between blood product transfusion, aprotinin use, or aspirin administration and adverse outcome in our study suggests that the complex interaction of factors affecting blood coagulation and hemostasis may play an important role in clinical outcome.

We found that the use of aprotinin and fresh-frozen plasma was more prevalent among German centers, despite relatively little difference in blood loss compared with the other 3 countries studied. It is possible that frozen plasma administration, in combination with aprotinin, may have conferred additional risk. Although the large majority of randomized studies comparing aprotinin with placebo or other antifibrinolytic agents have not suggested additional risk with aprotinin, 6 recent investigations reported that the use of aprotinin is associated with increased adverse outcomes. ${ }^{31-36}$ Therefore, our findings raise questions regarding the optimal hematologic management of patients who 
TABLE 3. Between-country differences in outcome

\begin{tabular}{|c|c|c|c|c|c|}
\hline Outcome variable, n (\%) & $\begin{array}{l}\text { United Kingdom } \\
\quad(\mathrm{n}=619)\end{array}$ & $\begin{array}{c}\text { Canada } \\
(n=444)\end{array}$ & $\begin{array}{l}\text { United States } \\
(n=1283)\end{array}$ & $\begin{array}{l}\text { Germany } \\
\text { (n= 834) }\end{array}$ & $P$ value \\
\hline In-hospital mortality (overall) & $9(1.5) \ddagger$ & $9(2.0)$ & $34(2.7)$ & $32(3.8)$ & .034 \\
\hline EuroSCORE 0-3 (low risk) & $2 / 363(0.6)$ & $0 / 219$ & $3 / 547(0.6)$ & $4 / 400(1.0)$ & .539 \\
\hline EuroSCORE 4-7 (medium risk) & $3 / 232(1.3)$ & $5 / 182(2.8)$ & $11 / 514(2.1)$ & $12 / 332(3.6)$ & .328 \\
\hline EuroSCORE $\geq 8$ (high risk) & 4/24 (16.7) & $4 / 43(9.3)$ & $20 / 222(9.0)$ & $16 / 102(15.7)$ & .245 \\
\hline Nonfatal morbidity & $68(11.0) \ddagger$ & $60(13.5)$ & $196(15.3)$ & $167(20.0)$ & $<.001$ \\
\hline Morbidity and/or mortality* & $77(12.4) \ddagger$ & $69(15.5)$ & $231(18.0)$ & $199(23.9)$ & $<.001$ \\
\hline \multicolumn{6}{|l|}{ Postoperative cardiac morbidity } \\
\hline $\mathrm{MI}$ & $42(6.8)$ & $14(3.2) \dagger$ & $86(6.7)$ & $93(11.2)$ & $<.001$ \\
\hline $\mathrm{CHF}$ & $21(3.4) \dagger$ & $43(9.7)$ & $96(7.5)$ & $88(10.6)$ & $<.001$ \\
\hline \multicolumn{6}{|l|}{ Postoperative cerebral morbidity } \\
\hline Encephalopathy & $1(0.2) \dagger$ & $5(1.1)$ & $16(1.2)$ & $24(2.9)$ & $<.001$ \\
\hline Stroke & $11(1.8)$ & $10(2.3)$ & $25(2.0)$ & $17(2.0)$ & .956 \\
\hline \multicolumn{6}{|l|}{ Postoperative renal morbidity } \\
\hline Renal failure & $4(0.6)$ & $4(0.9)$ & $21(1.6)$ & $39(4.7) \dagger$ & $<.001$ \\
\hline Renal dysfunction & $12(1.9) \dagger$ & $10(2.3) \dagger$ & $49(3.8)$ & $36(4.3)$ & .034 \\
\hline \multicolumn{6}{|c|}{ Postoperative gastrointestinal morbidity } \\
\hline GI ischemia/infarction & $4(0.6)$ & $0(0.0)$ & $3(0.2)$ & $4(0.5)$ & .257 \\
\hline
\end{tabular}

CHF, Congestive heart failure; EuroSCORE, European System for Cardiac Operative Risk Evaluation; Gl, gastrointestinal; MI, myocardial infarction. *Composite outcome. †Country with statistically different incidence $(P<.01$ with Bonferroni adjustment) in outcome, by pairwise comparisons. $\ddagger$ Statistically different incidence $(P<.01$ with Bonferroni adjustment) in outcome only comparing United Kingdom and Germany. After adjustment for confounders, country no longer had an independent effect on the risk of the composite outcome within 48 hours.

undergo $\mathrm{CABG}$ in general and the coincident use of aprotinin with frozen plasma, platelets, or other prothrombotic agents.

Geographic variability has been reported to exist for cost, length of stay, volume, and access to and adverse events after CABG surgery, ${ }^{35,37,38}$ although no previous studies have prospectively evaluated the processes of care and outcomes in the range of countries examined in this investigation. Peterson and colleagues ${ }^{39}$ found that the hospital at which CABG surgery was performed was the strongest predictor of prolonged stay, although there was also limited correlation between mortality and other outcomes.

TABLE 4. Multivariate analysis for composite outcome: Admission, preoperative, and intraoperative risk factors

\begin{tabular}{|c|c|c|c|}
\hline Variable & $\begin{array}{l}\text { Incidence of composite outcome in subgroup } \\
\text { No./total (\%) }\end{array}$ & $\begin{array}{l}\text { Adjusted OR } \\
\text { (95\% CI) }\end{array}$ & $P$ value \\
\hline \multicolumn{4}{|l|}{ By country } \\
\hline Germany vs United Kingdom & 199/834 (23.9) & $1.92(1.42-2.60)$ & $<.001$ \\
\hline United States vs United Kingdom & $231 / 1283(18.0)$ & $1.09(0.81-1.46)$ & .585 \\
\hline Canada vs United Kingdom & $69 / 444(15.5)$ & $1.21(0.84-1.74)$ & .306 \\
\hline United Kingdom (reference group) & $77 / 619(12.4)$ & 1.00 & \\
\hline \multicolumn{4}{|l|}{ By patient } \\
\hline \multicolumn{4}{|l|}{ EuroSCORE risk group } \\
\hline Low risk (0-3) & $193 / 1529(12.6)$ & $1.55(1.34-1.79)$ & $<.001$ \\
\hline Medium risk (4-7) & $241 / 1260(19.1)$ & & \\
\hline High risk $(\geq 8)$ & 142/391 (36.3) & & \\
\hline Warfarin/Coumadin use within $1 \mathrm{wk}$ before revascularization & $60 / 198(30.3)$ & $1.73(1.23-2.43)$ & .002 \\
\hline Heart failure at admission & $175 / 633(27.7)$ & $1.60(1.28-2.01)$ & $<.001$ \\
\hline Renal disease history & $145 / 511(28.4)$ & $1.30(1.00-1.69)$ & .047 \\
\hline Creatinine $>1.3 \mathrm{mg} / \mathrm{dL}$ on admission & $131 / 454(28.9)$ & $1.54(1.17-2.02)$ & .002 \\
\hline \multicolumn{4}{|l|}{ By practice } \\
\hline Transfusion of fresh-frozen plasma, intraoperative & $79 / 217(36.4)$ & $1.52(1.03-2.25)$ & .034 \\
\hline Transfusion of platelets, intraoperative & $66 / 196(33.7)$ & $1.56(1.03-2.37)$ & .035 \\
\hline
\end{tabular}

Cl, Confidence interval; OR, odds ratio; EuroSCORE, European System for Cardiac Operative Risk Evaluation. (Country included as categoric variable, United Kingdom $=$ reference group.) 
TABLE 5. Multivariate analysis for composite outcome within 48 hours postsurgery: Admission, preoperative, and intraoperative risk factors

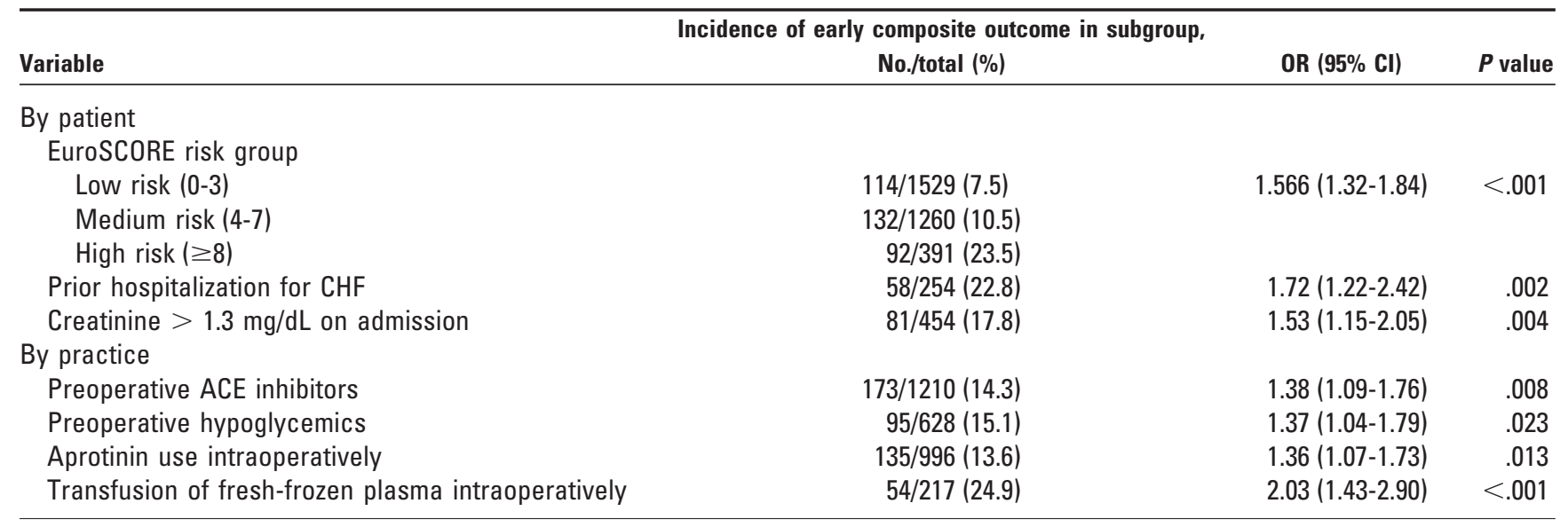

The waiting list time may impact outcome in that a country with a longer list time (eg, the United Kingdom) may effectively exclude sicker patients. On the other hand, longer wait times also have been shown to result in clinical deterioration, which could then predispose to worse outcomes in those patients waiting longer. ${ }^{40}$ However, we found no substantial differences among the countries regarding acute or chronic disease severity at the time of surgery, suggesting that if wait time did play a role, its effects may have been mitigated.

This study has some limitations. The patient selection procedures may not be representative of the countries studied, although the average volume of cardiac cases in centers that participated in EPI-II exceeded 1200 patients per year. We chose the EuroSCORE for risk adjustment because it is an established index using data from European patients.
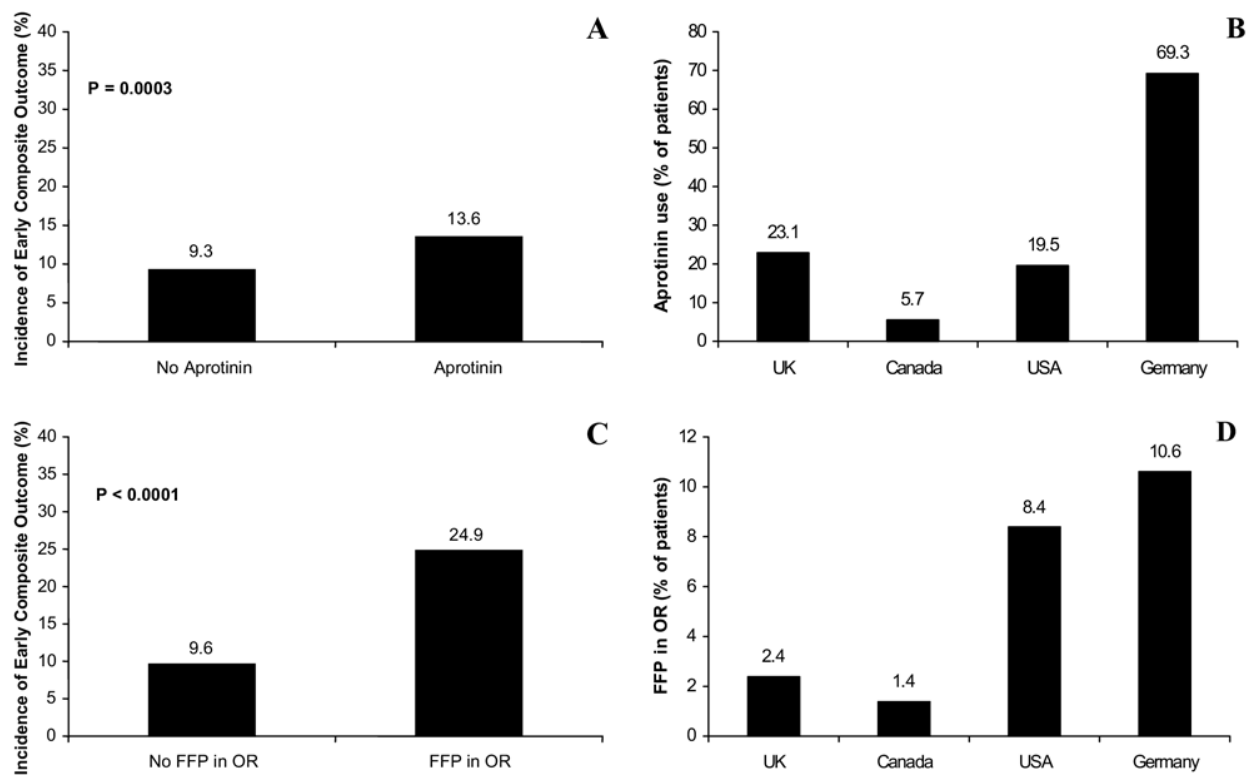

Figure 2. Factors explaining country differences in early composite outcome within 48 hours postsurgery. Incidence of composite outcome within $\mathbf{4 8}$ hours postsurgery by use of aprotinin ( $A$ and $B$ ) and fresh-frozen plasma transfusion (C and D). Use of risk factors within each study country: United Kingdom, Canada, United States, and Germany. Data given in percentages. FFP, Fresh-frozen plasma; OR, operating room. 
TABLE 6. Multivariate analysis for composite outcome 48 hours postsurgery: Admission, preoperative, intraoperative, and postoperative (within 48 hours) risk factors

\begin{tabular}{|c|c|c|c|}
\hline Variable & $\begin{array}{l}\text { Incidence of late composite outcome in subgroup, } \\
\text { No./total (\%) }\end{array}$ & OR $(95 \% \mathrm{Cl})$ & $P$ value \\
\hline \multicolumn{4}{|l|}{ By patient } \\
\hline \multicolumn{4}{|l|}{ EuroSCORE risk group } \\
\hline Low risk (0-3) & $79 / 1415(5.6)$ & $1.54(1.25-1.88)$ & $<.001$ \\
\hline Medium risk (4-7) & $109 / 1128(9.7)$ & & \\
\hline High risk $(\geq 8)$ & $50 / 299(16.7)$ & & \\
\hline Heart failure on admission & $69 / 527(13.1)$ & $1.60(1.16-2.21)$ & .004 \\
\hline \multicolumn{4}{|l|}{ By practice } \\
\hline Aspirin use within $48 \mathrm{~h}$ postsurgery & $114 / 1853(6.2)$ & $0.56(0.42-0.73)$ & $<.001$ \\
\hline Heparin use within $48 \mathrm{~h}$ postsurgery & $102 / 975(10.5)$ & $1.51(1.14-2.00)$ & .004 \\
\hline $\begin{array}{l}\text { Transfusion of fresh-frozen plasma intraoperatively } \\
\text { or within } 24 \mathrm{~h} \text { postsurgery }\end{array}$ & $71 / 467(16.4)$ & $1.95(1.42-2.67)$ & $<.001$ \\
\hline
\end{tabular}

Cl, Confidence interval; OR, odds ratio; EuroSCORE, European System for Cardiac Operative Risk Evaluation.

Although some studies have suggested that the EuroSCORE can accurately predict short and long-term outcomes in North American patients, it is possible that it is less accurate in our non-European cohort. There may have been changes in the frequency of CABG surgery or the use of alternative techniques since completion of study enrollment, but the lack of major changes in the management of patients undergoing $\mathrm{CABG}$ with cardiopulmonary bypass makes our data current and applicable to this population. Finally, despite prospective data collection, it is possible that unmeasured confounders may exist that could have affected either the risk adjustment or the strength of the outcome associations.

\section{Conclusions}

We found significant between-country differences in adverse vascular outcomes, as well as processes of care, in patients who underwent CABG surgery. In particular, the use of blood products, antifibrinolytics, and antithrombotic agents differed significantly and appeared to be significantly associated with the differences in outcome. Clearly, causal-
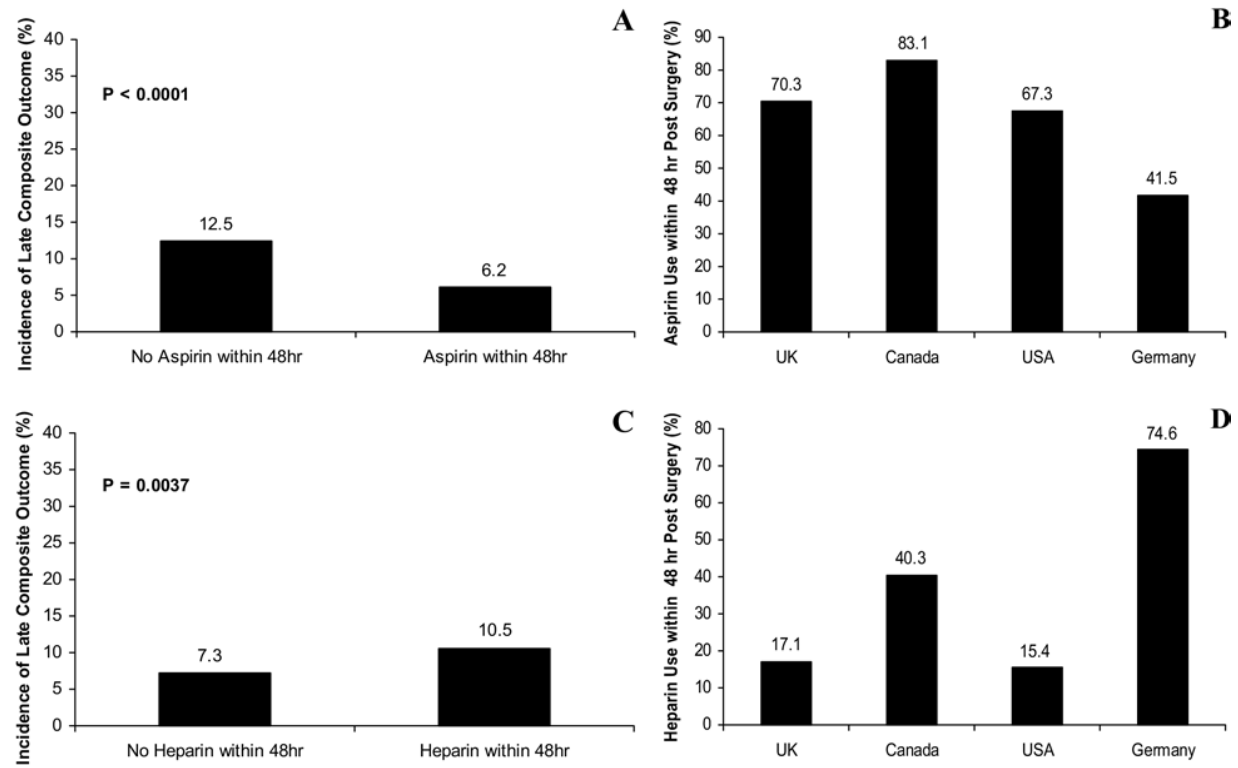

Figure 3. Factors explaining country differences in late composite outcome 48 hours postsurgery. Incidence of composite outcome 48 hours postsurgery by early use (within 48 hours postsurgery) of aspirin (A and B) and heparin (C and D). Use of risk factors within each study country: United Kingdom, Canada, United States, and Germany. Data given in percentages. 
ity cannot be invoked; however, among those countries that more commonly used early aspirin therapy and avoided blood product transfusion and use of aprotinin, outcomes were improved. Therefore, we surmise that hematologic practice plays a critical role in determining the frequency of adverse outcomes after CABG surgery.

Our appreciation to Brenda Xavier, business manager for the Multicenter Study of Perioperative Ischemia Research Group, and Diane Beatty, administrative assistant at The Ischemia Research and Education Foundation, for their efforts in bringing this article through the various editorial stages.

\section{References}

1. Mangano DT. Cardiovascular morbidity and CABG surgery-a perspective: epidemiology, costs, and potential therapeutic solutions. J Card Surg. 1995;10:366-8.

2. van Eck FM, Noyez L, Verheugt FW, Brouwer RM. Changing profile of patients undergoing redo-coronary artery surgery. Eur J Cardiothorac Surg. 2002;21:205-11.

3. Weintraub WS, Craver JM, Jones EL, Gott JP, Deaton C, Culler SD, et al. Improving cost and outcome of coronary surgery. Circulation. 1998;98:I123-8.

4. Unger F. Cardiac interventions in Europe 1997: coronary revascularization procedures and open heart surgery. Cor Europaeum. 1999;7: $177-89$.

5. Kingma JH. Waiting for coronary artery bypass surgery: abusive, appropriate, or acceptable? Lancet. 1995;346:1570-1.

6. Rosenthal MB, Newhouse JP. Managed care and effective rationing. $J$ Health Care Finance. 2002;28:1-10.

7. Longo KM, Cowsen ME, Flaum MA, Valsania P, Schork MA, Wagner LA, et al. Preoperative predictors of cost in Medicare-age patients undergoing coronary artery bypass grafting. Ann Thorac Surg. 1998; $66: 740-5$.

8. Loubani M, Mediratta N, Hickey MS, Galinanes M. Early discharge following coronary bypass surgery: is it safe? Eur J Cardiothorac Surg. 2000;18:22-6.

9. Cheng DC. Fast-track cardiac surgery: economic implications in postoperative care. J Cardiothorac Vasc Anesth. 1998;12:72-9.

10. Haehnel JC, Roth P, Lohmann E, Meisner H, Hehrlein FW. Implications of the introduction of fixed reimbursement rates in Germany. Thorac Cardiovasc Surg. 1996;44:97-102.

11. Silber S, Muhling H, Dorr R, Zindler G, Preuss A, Stumpfl A. Waiting times and death on the waiting list for coronary artery bypass operation. Experiences in Munich with over 1,000 patients. Herz. 1996;21: 389-96.

12. Bernstein SJ, Rigter H, Brorsson B, Hilborne LH, Leape LL, Meijler $\mathrm{AP}$, et al. Waiting for coronary revascularization: a comparison between New York State, The Netherlands and Sweden. Health Policy. 1997;42:15-27.

13. Shore-Lesserson L. Myocardial injury in cardiac surgery: the role of transfusion. J Cardiothorac Vasc Anesth. 2000;4:11-4.

14. Mangano DT, for the Multicenter Study of Perioperative Ischemia (McSPI) Research Group. Aspirin and mortality from coronary bypass surgery. N Engl J Med. 2002;347:1309-17.

15. Mangano DT. Perioperative cardiac morbidity. Anesthesiology. 1990; 72:153-84.

16. Roach GW, Kanchuger M, Mora Mangano CT, Newman MF, Nussmeier NA, Wolman R, et al. for the Multicenter Study of Perioperative Ischemia (McSPI) Research Group. Adverse cerebral outcomes after coronary bypass surgery. $N$ Engl J Med. 1996;335:1857-63.

17. Mora Mangano CT, Diamondstone LS, Ramsay JG, Aggarwal A, Herskowitz A, Mangano DT, for the Institutions of the Multicenter Study of Perioperative Ischemia (McSPI) Research Group. Renal dysfunction following myocardial revascularization: risk factors, adverse outcomes and hospital resource utilization. Ann Intern Med. 1998;128:194-203.
18. Fitzgerald T, Kim D, Karakois S, Alam H, Provido H, Kirkpatrick J. Visceral ischemia after cardiopulmonary bypass. Am Surg. 2000;66: 623-6.

19. Nashef SA, Roques F, Hammill BG, Peterson ED, Michel P, Grover FL, et al. Validation of European System for Cardiac Operative Risk Evaluation (EuroScore) in North American cardiac surgery. Eur J Cardiothorac Surg. 2002;22:101-5.

20. Tinmouth A, Macdougall L, Fergusson D, Amin M, Graham ID, Hebert PC, et al. Reducing the amount of blood transfused: a systematic review of behavioral interventions to change physicians' transfusion practices. Arch Intern Med. 2005;165:845-52.

21. Stover EP, Siegel LC, Parks R, Levin J, Body SC, Maddi R, et al., for the Multicenter Study of Perioperative Ischemia (McSPI) Research Group. Variability in transfusion practice for coronary artery bypass surgery persists despite national consensus guidelines: a 24-institution study. Anesthesiology. 1998;88:327-33.

22. Goodnough LT, Johnston MFM, Toy PT, Transfusion Medicine Academic Award Group. The variability of transfusion practice in coronary artery bypass surgery. JAMA. 1991;265:86-90.

23. Boldt J, Kling D, von Bormann B, Zuge M, Hempelmann G. Homologous fresh frozen plasma in heart surgery. Myth or necessity. Anaesthesist. 1989;38:353-9.

24. Boldt J, Knothe C, Zickman B. Platelet function in cardiac surgery: influence of temperature and aprotinin. Ann Thorac Surg. 1993;55: 652-8.

25. Menges T, Rupp D, van Lessen A, Hempelmann G. Measure for reducing the use of homologous blood. Effects of blood coagulation during total endoprosthesis. Anaesthesist. 1992;41:27-33.

26. Trimble AS, Osborn JJ, Kerth WJ, Gerbode F. The prophylactic use of fresh frozen plasma after extracorporeal circulation. $J$ Thorac Cardiovasc Surg. 1964;48:314-6.

27. Kasper GC, Welling RE. Anticoagulation: the rest of the story. Curr Surg. 2001;58:353-7.

28. Wilhelmi M, Franke U, Cohnert T, Weber P, Kaukemuller J, Fischer $\mathrm{S}$, et al. Coronary artery bypass grafting surgery without the routine application of blood products: is it feasible? Eur J Cardiothorac Surg. 2001;19:657-61.

29. Consten EC, Henny CP, Eijsman L, Dongelmans DA, van Oers MH The routine use of fresh frozen plasma in operations with cardiopulmonary bypass is not justified. J Thorac Cardiovasc Surg. 1996;112: 162-7.

30. Spiess BD. Risks of transfusion: outcome focus. Transfusion. 2004; 44:4S-14S.

31. Mangano DT, Tudor IC, Dietzel C, for the Multicenter Study of Perioperative Ischemia (MCSPI) Research Group and the Ischemia Research and Education Foundation. The risk associated with aprotinin in cardiac surgery. $N$ Engl J Med. 2006;354:353-65.

32. Ad N, Barnett S, Hunt S, Fitzgerald D, Speir A. The use of aprotinin in cardiac surgery is associated with increased risk of renal failure and neurological events. Circulation. 2006;114:II-476.

33. Brown JR, Birkmeyer NJO, O'Connor GT. Aprotinin in cardiac surgery. N Engl J Med. 2006;354:1954-5.

34. Karkouti K, Beattie WS, Dattilo KM, McCluskey SA, Ghannam M, Hamdy A, et al. Blood conservation and transfusion alternatives: a propensity score case-controlled comparison of aprotinin and tranexamic acid in high-transfusion-risk cardiac surgery. Transfusion. 2006; 46:327-38.

35. Cowper PA, DeLong ER, Peterson ED, Lipscomb J, Muhlbaier LH, Jollis JG, et al. Geographic variation in resource use for coronary artery bypass surgery. IHD Port Investigators. Med Care. 1997;35: 320-33.

36. Mangano DT, Miao Y, Vuylsteke A, et al., for the Multicenter Study of Perioperative Ischemia (McSPI) Research Group and the Ischemia Research and Education Foundation. Mortality associated with aprotinin during 5 years following cardiac artery bypass graft surgery. JAMA. 2007;297:471-9.

37. Nalysnyk L, Fahrbach K, Reynolds MW, Zhao SZ, Ross S. Adverse events in coronary artery bypass graft $(\mathrm{CABG})$ trials: a systematic review and analysis. Heart. 2003;89:767-72. 
38. Gregory PM, Malka ES, Kostis JB, Wilson AC, Arora JK, Rhoads GG. Impact of geographic proximity to cardiac revascularization services on service utilization. Med Care. 2000;38:45-57.

39. Peterson ED, Coombs LP, Ferguson TB, Shrover AL, DeLong ER, Grover FL, et al. Hospital variability in length of stay after coronary artery bypass surgery: results from the Society of Thoracic Surgeon's National Cardiac Database. Ann Thorac Surg. 2002;74:464-73.

40. Sampalis J, Boukas S, Liberman M, Reid T, Dupuis G. Impact of waiting time on the quality of life of patients awaiting coronary artery bypass grafting. CMAJ. 2001;165:429-33.

\section{Appendix}

The Ischemia Research and Education Foundation is an independent nonprofit foundation, formed in 1987, that develops clinical investigators through observational studies and clinical trials addressing ischemic injury of the heart, brain, kidney, and gastrointestinal tract. The Ischemia Research and Education Foundation provided all funding for execution of the study, collection of the data, and analysis and publication of the findings. The Multicenter Study of Perioperative Ischemia Research Group, formed in 1988, is an association of 160 international medical centers located in 23 countries, organized through, and supported by grants from the Ischemia Research and Education Foundation.

The following institutions and persons coordinated the Multicenter Study of Perioperative Ischemia EPI-II study. Study Chairman-D. Mangano; Senior Editor-J. Levin, L. Saidman; Study Design and Analysis Center: Ischemia Research and Education Foundation-P. Barash, C. Dietzel, A. Herskowitz, Y. Miao, I. C. Tudor; Editorial/Administrative Group-D. Beatty, I. Lei, B. Xavier.

The following institutions and persons participated in the Multicenter Study of Perioperative Ischemia EPI-II Study. Centers and investigators: United States-University of Chicago, Weiss Memorial Hospital—S. Aronson; Beth Israel Hospital-M. Comunale; Massachusetts General-M. D'Ambra; University of Rochester-M. Eaton; Baystate Medical Center-R. Engelman; Baylor College of Medicine-J. Fitch; Duke Medical Center-K. Grichnik; UTHSCSA-Audie Murphy VA, UTHSCSA-University HospitalC. B. Hantler; St Luke's Roosevelt Hospital—Z. Hillel; New York University Medical Center-M. Kanchuger, J. Ostrowski; Stanford University Medical Center-C. M. Mangano; Yale University School of Medicine-J. Mathew, M. Fontes, P. Barash; University of Wisconsin-M. McSweeney, R. Wolman; University of Arkan- sas for Medical Sciences-C. A. Napolitano; Discovery Alliance, Inc.-L. A. Nesbitt; VA Medical Center, Milwaukee-N. Nijhawan; Texas Heart Institute, Mercy Medical Center-N. Nussmeier; University of Texas Medical School, Houston-E. G. Pivalizza; University of Arizona-S. Polson; Emory University Hospital—J. Ramsay; Kaiser Foundation Hospital—G. Roach; Thomas Jefferson University Hospital, MCP Hahnemann University Hospital-N. Schwann; VAMC Houston-S. Shenaq; Maimonides Medical Center-K. Shevde; Mt Sinai Medical Center-L. Shore-Lesserson, D. Bronheim; University of Michigan-J. Wahr; University of WashingtonB. Spiess; VA Medical Center, SF-A. Wallace; Austria-University of Graz-H. Metzler; Canada-University of British Columbia-D. Ansley, J. P. O'Connor; The Toronto Hospital-D. Cheng; Laval Hospital, Quebec-D. Côte; Health Sciences Centre-University of Manitoba-P. Duke; University of Ottawa Heart Institute-J. Y. Dupuis, M. Hynes; University of Alberta Hospital-B. Finegan; Montreal Heart Institute-R. Martineau, P. Couture; St Michael's Hospital, University of Toronto-D. Mazer; Colombia-Fundacion Clinico Shaio-J. C. Villalba, M. E. Colmenares; France-CHRU Le Bocage-C. Girard; Hospital Pasteur-C. Isetta; GermanyUniversität Würzburg - C. A. Greim, N. Roewer; Universität BonnA. Hoeft; University of Halle-R. Loeb, J. Radke; Westfalische Wilhelms-UniversitätMunster-T.Mollhoff;UniversitätHeidelbergJ. Motsch, E. Martin; Ludwig-Maximillians Universität-E. Ott; Ludwig-Maximillians Universität-P. Ueberfuhr (Department of Cardiac Surgery); Universität Krankenhaus Eppendorf-J. Scholz, P. Tonner; Georg-AugustUniversitätGöttingen-H. Sonntag; HungaryOrszagos Kardiologiai Intezet-A. Szekely; India-Escorts Heart Institute-R. Juneja; Apollo Hospital—G. Mani; Israel—Hadassah University Hospital-B. Drenger, Y. Gozal, E. Elami; Italy-San Raffaele Hospital, Universita de Milano-C. Tommasino; MexicoInstituto Nacional de Cardiologia-P. Luna; The NetherlandsUniversity Hospital Maastricht-P. Roekaerts, S. DeLange; PolandInstitute of Cardiology-R. Pfitzner; Romania-Institute of Cardiology—D. Filipescu; Thailand-Siriraj Hospital—U. Prakanrattana; United Kingdom-Glenfield Hospital-D. J. R. Duthie; St. Thomas' Hospital-R.O. Feneck; The Cardiothoracic Centre, Liverpool-M. A. Fox; South Cleveland Hospital-J. D. Park; Southhampton General Hospital—D. Smith; Manchester Royal Infirmary-A. Vohra; Papworth Hospital—R. D. Latimer, A. Vuylsteke. 